benoeming heeft plaats gehad. De tweewielige kruiwagen is plaatselijk nóg wel in gebruik, en ik werd dan ook onmiddellijk aan de begripsverschuiving bij $\check{\alpha} \mu a \xi \alpha$ herinnerd, toen ik voor eenigen tijd in Romaansch Zwitseriand, ergens tusschen Reichenau en Ilanz, zulk een tweewielig vehikel zag. Iets anders zijn weer de tweewielige handkarretjes, die ook wel brouette genoemd worden.

Maar Zwitserland biedt nog een veel treffender parallel. Want terwijl *bisrotitta zich semantisch ontwikkelde in de richting van éenwieler, vertoonen de nazaten van het Vulgairlat. "birotium plaatselijk de beteekenis van „voertuig met vier raderen", evenals ã $\mu a \xi a$ dus. Bedoeld voertuig is een vrachtwagen, met name een hooiwagen, en ik geloof zelfs bij machte te zijn aan de hand van de verschilleride berichten van Horning in de Zeitschrift für roman. Philologie, XVIII (1894), bl. 234, XXIV (1900), bl. 552, en XXV (1901), bl. 505 zijn ontwikkelingsgeschiedenis te kunnen rekonstrueeren. Het voges. brŏ, lothar. brŏ, prov. bros, engad. bröz enz. beteekent gewoon een kar met twee raderen, plaatselijk meer bepaald mestkar. Voor de Vogezen wordt uitdrukkelijk het onderscheid gemaakt, dat de brŏ een dissel in het midden heeft, terwijl de šarăt "charrette" een tweewielig wagentje met zeelen (brancards) is. Maar in de buurt van Neuchâtel kreeg het verwante berosse een andere beteekenis. Daar toch werd de kar met twee raderen in den oogsttijd somwijlen tot het vervoer van grooter hoeveelheden ingericht door er wagenladders op te plaatsen, zoodat het voertuig inderdaad een vrachtwagen werd, die dan ook weldra vier raderen vereischte. De naam berosse ging nu plaatselijk over op de ladders (zoo b.v. te Cressier) en op het vervormde voertuig, te Cortaillod eigenaardig genoeg op de handeling zelf: "la transformation du char en voiture à foin par les échelles". Wellicht vindt men de beteekenis "vierwielige wagen" ook nog in sommige Italiaansche dialekten.

Zou men wellicht een overeenkomstig proces in overoude Grieksche tijden mogen veronderstellen? Zou wellicht ook de tweewielige \&ँ $\mu \alpha \xi \alpha$ aanvankelijk slechts in bepaalde omstandigheden tot vrachtwagen vervormd zijn, om ten slotte blijvend dien vorm aan te nemen? Mij dunkt we hebben eenigermate het recht hiertoe te besluiten, óok uit het feit, dat $\alpha \mu a \xi \alpha$ bij Homerus nog niet doorgaans den vrachtwagen beteekent, maar slechts het onderstel. De vrachtwagen heet $\dot{\alpha} \boldsymbol{\jmath} \dot{\eta} \boldsymbol{\nu} \eta$. In de Ilias XXIV, 189 zien we hoe Priamus zijn zonen beveelt, den wagen klaar te maken om het lijk van Hektor te vervoeren:

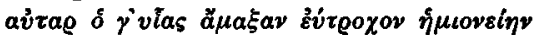

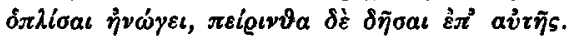

Zou de $a \tilde{\mu \alpha} \xi a$ soms op den duur vierwielig geworden zijn, doordat er dikwijls, zooals hier, een ruime, zware wagenbak op geplaatst werd? Ik denk natuurlijk aan de wagenladders in het gebied van Neuchâtel.

Utrecht.

Jos. SCHRIJNEN.

\title{
DE INFINITIVUS FUTURI IN HET GRIEKSCH EN IN HET NEDERLANDSCH.
}

Het onderwerp, dat prof. Hesseling in dezen jaargang, p. $75 \mathrm{vgg}$. behandeld heeft, "de infinitivus futuri in het Grieks en in het Nederlands", trok mijn 
bijzondere aandacht. Eenige jaren geleden immers (Weekbl. v. gymn. en midd. O., XII. 1916 p. 1178) heb ik terloops het goed recht der infinitivi aoristi na verba, die volgens de schoolsche lear een inf. futuri regeeren, met een enkel woord verdedigd en een uitvoeriger opstel daarover aangekondigd. Wel heb ik daarna, in een art. ter begeleiding van mijne bewerking van Cobets uitgave van Xenophons Hellenica (Leiden, Brill, 1916), alle dergelijke. gevallen in de Hellenica, waar men vroeger den infinitivus aoristi elimineerde, in denzelfden geest besproken (t. a. p. XIII, 1916, p. 405), maar het eigeniijke door mij in uitzicht gestelde artikel bleef ten gevolge van allerhand omstandigheden tot dusverre ongeschreven. Door de verschijning van het artikel van prof. Hesseling kan ik mij thans gelukkig van deze taak ontheven achten.

Het is natuurlijk niet om dezen loop van zaken in het licht te stellen, dat $\mathrm{ik}$ hier nog even op de kwestie wil terugkomen. De aanleiding daartoe is prof. Hesselings beantwoording der vraag, die voor hem zelf weer de aanleiding tot zijn opstel is geweest (p. 80): "waarom hebben zich juist de Nederlanders het meest geërgerd aan die vervanging van infinitivi futuri?" "Cobet en de zijnen verkeerden onbewust onder den invloed van hun moedertaal, toen zij de veroordeelde verbinding zo streng vervolgden" (t. a. p.).

De juistheid van deze verklaring zou ik willen in twijfel trekken. Is, zou ik voorshands wenschen te vragen, de veelvuldigheid van het verschijnsel bij onze Nederlandsche philologen, vergeleken bij de buitenlanders, in werkelijkheid niet meer schijn dan wezen? Cobet immers hanteerde o. a. bepaalde emendatietypes. Hij heeft school gemaakt zooals weinige geleerden in ons land. Zijne talrijke adepten legden zich er o. a. op toe dergelijke schoolsche conjecturentypes van den meester bij hun lectuur der schrijvers in toepassing te brengen. De mogelijkheid hiertoe bestond te gereeder, waar Cobet, ongeëvenaard als zijn kennis van het Grieksch was, zich bij het trekken van de scheidingslijn tusschen het goede en het verkeerde, vaker liet leiden door zijn persoonlijk gevoel dan door de overlevering. Mag dus het groote aantal zijner volgelingen, die een bepaald conjectuurtype in praktijk brachten, wel gewicht in de schaal leggen bij het opsporen van den psychologischen ondergrond er van? M. i. hebben wij in dergelijke gevallen alleen op Cobet zelf te letten, en dan acht ik het reeds bij voorbaat aan twijfel onderhevig, of Cobet, die te Parijs geboren was, die in zijn omvangrijk œuvre nooit, op één uitzondering na, zich van het Nederlandsch bediend heeft, bij zijn emendaties onbewust door zijn Nederlandsch taalgevoel beïnvloed is.

Doch voor het bijzonder geval betreffende de vervanging van den overgeleverden infinitivus aoristi (of praesentis) door een inf. futuri na de verba sperandi, iurandi etc. gevoel ik dezen twijfel nog sterker. Juist onze moedertaal biedt geen richtsnoer - prof. Hesseling heeft er trouwens zelf (p. 81) aan herinnerd - voor een strenge gebruikswijze van den inf futuri, zij verbindt met de ww. van hopen een inf. praesentis en laat bij die van beloven dezen inf. even goed als dien van het futurum toe. Veeleer was het een andere taal, welker strikt gebruik van den inf. futuri na de onderhavige groep verba Cobet zich tot maatstaf bij de beoordeeling der Grieksche constructies nam: het klassieke Latijn, welks invloed door prof. Hesseling 
evenmin geheel wordt uitgeschakeld (t. a. p.) ${ }^{1}$ ). De tempusleer van het Grieksch immers werd omstreeks het midden der vorige eeuw en ten onzent en elders geheel naar die van het Latijn beoordeeld. Dat in het Grieksch naast tempus ook actio een belangrijke rol speelt, is omstreeks denzelfden tijd eerst door de taalwetenschap, vooral door Georg Curtius, aangetoond geworden. Dit inzicht is tot de klassiek-philologen in het algemeen en tot onze Nederlandsche in het bijzonder niet bepaald snel doorgedrongen.

Het verschijnsel uit de tempusleer en zijn behandeling door de conjecturaalkritiek, dat ons heeft beziggehouden, bezit een volkomen analogon in de vervanging in bijzinnen van overgeleverde imperfecta door plusquamperfecta, welke bij buitenlandsche philologen gevonden wordt en bij Cobet en zijn school eveneens tot emendatietype is geworden. Dit type berust op een tastbare overbrenging der strenge Latijnsche consecutio temporum op het Grieksch, dat, gelijk men eerst in de tweede helft der 19e eeuw is gaan inzien, een tempus mist om een in het verleden afgeloopen handeling uit te drukken. Daar dergelijke imperfecta, vooral bij verba die geen reduplicatie toelaten,

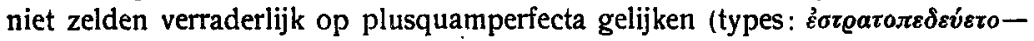

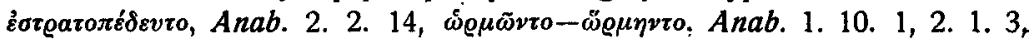
vgl. Weekbl. XI, 1915, p. 823), konden Cobet en de zijnen deze imperfecta, wanneer zij schijnbaar de beteekenis van Latijnsche plusquamperfecta hadden, als een verwording beschouwen, waarvan de schuld lag bij den een of anderen onwetenden Graeculus.

Amsterdam.

M. BOAS.

\section{BOEKBEOORDEELINGEN.}

Hermann Paul, Deutsche Grammatik, Band II. Teil III: Flexionslehre. Halle a. S., Max Niemeyer, 1917 (VI und 345 Seiten. - M. 8.-).

Schon ein Jahr nach dem I. Bande 2) konnte Paul den II. Band seiner Deutschen Grammatik der Öffentlichkeit übergeben. Der Text dieses III. Teiles des ganzen Werkes umfasst beinahe 279 Seiten, während ein ausführliches doppelspaltiges 'Wörterverzeichnis' zu den beiden Bänden die übrigen 65 Seiten ausfüllt. Mit Bezug auf die weitere Ökonomie der Flexionslehre sei gleich bemerkt, dass die 'Substantiva' mit $118 \S \S$ bis auf ,Seite 163 reichen, wogegen die 'Verba' nur 61 \$§ auf ungefähr 90 Seiten beanspruchen: von S. 189 bis auf S. 279. Zwischen diesen beiden ungleichen, aber stark hervorstehenden Flügeln nehmen sich die den geringen Mittelbau bildenden 'Adjektiva', 'Pronomina' und 'Zahlwörter' - bezw. mit 7 \$\$ auf 7 Seiten, 13 \$\$ auf ungefähr 14 Seiten und 4 \$§ auf ungefähr 4 Seiten - bescheiden genug aus. Aber das ist nun einmal stofflich bedingt und findet sich bekanntlich in entsprechenden Proportionen in jeder deutschen Grammatik. Der Umfang der 'Substantiva' gegenüber dem Raum, den die 'Verba' einnehmen, ist aber

1) Wanneer Cobet in zijn Misecllanea critica (1876) p. 330 op een plaats bij Homerus (I1. 20,86 ) na een verbum van beloven een inf. futuri herstelt in plaats van een inf. praesentis, verdedigt hij deze conjectuur kortweg: non hoc erat pollicitus $p$ ugnare se, sed pugnaturum.

2) Vgl. die Anzeige dieses Bandes in dieser Zs. III, 307/12, wo auf S. 310, Zeile 16, der störende Druckfehler 'unhöflich' in 'unhöfisch' zu berichtigen ist. 